\title{
O MOVIMENTO FEMINISTA E A PSICOLOGIA
}

\section{The Feminist Movement and Psychology}

\author{
Denise Rodrigues Prehn ${ }^{1}$ \\ Simone M. Hüning ${ }^{2}$
}

\section{Resumo}

O presente trabalho constitui uma reflexão sobre o impacto que os pressupostos do Movimento Feminista têm causado na produção teórica da Psicologia, provocando uma revisão de suas metodologias e conceitos, e levando a uma nova abordagem científica preocupada agora com o desenvolvimento de formas alternativas de análise das relações entre as mulheres e os homens. Contestando o viés androcêntrico da ciência moderna, o Movimento Feminista promoveu o desenvolvimento de formas alternativas de análise das relações entre homens e mulheres e provocou o que poderíamos chamar de uma virada epistemológica nas ciências sociais. Fez-se uma breve alusão ao enquadramento histórico subjacente à emergência da Psicologia, bem como aos princípios que estiveram na base de seu desenvolvimento como ciência. Em seguida aborda-se o modo como o questionamento desses princípios tem levado a Psicologia a compreender o enquadramento das pessoas (mulheres e homens) no mundo social envolvente, a tomada de perspectiva do ser humano com base em aspectos relacionais. Este trabalho pretende abordar os desafios propostos pelo Movimento Feminista à Psicologia e as repercussões de tais questionamentos em suas práticas.

Palavras-chave: Psicologia; Metodologias Feministas; Feminismo.

1 Mestre em Psicologia Social e da Personalidade; doutoranda do PPG em Psicologia da PUCRS.

2 Mestre em Psicologia Social e da Personalidade - PUCRS; doutoranda do PPG em Psicologia da PUCRS/CNPq. Endereço para contato: PPG de Psicologia - PUCRS - Av. Ipiranga, 6681- Prédio 11/9 andar - Partenon - Porto Alegre/RS CEP: 90619-900.

E-mail: simonehuning@yahoo.com.br ; prehn@zaz.com.br. 


\section{Abstract}

This paper constitutes a reflection on the impact that the assumptions of the Feminist Movement have caused in the theoretical production of Psychology, enabling a review of its methodologies and concepts. Thus, bringing on a new scientific approach now concerned with the development of alternative forms of analysis of the relation between women and men. Contesting the androcentric view of modern science, the Feminist Movement has promoted the development of alternative forms of analysis of the relation between men and women and has caused what we could call na epistemological twist in Social Sciences. A brief allusion was made concerning the historical context underlying the emergence of Psychology, as well as the assumptions that sustained its development as a science. Next we approach the way in which the questioning of these assumptions have taken Psychology to understand the framing of people (men and women) into the entangling social world, the human being and its relational aspects in perspective. This work aims to approach the challenges proposed by the Feminist Movement to Psychology and the repercussions of such questionings in its practices.

Keywords: Psychology; Feminist Methodology; Feminism.

Em meados do século XX, o Movimento Feminista $(\mathrm{MF})^{3}$ ressurgiu como um dos movimentos sociais mais importantes da atualidade, desencadeando questionamentos a respeito dos modelos teóricos seguidos por diversas ciências, principalmente as que têm como objeto de estudo as relações sociais; como não poderia deixar de ser, a Psicologia é uma delas. No que diz respeito especificamente a esta ciência, seu impacto tem sido bastante significativo, provocando revisões de suas metodologias e conceitos, e levando a novas formas de abordar cientificamente os sujeitos e suas relações.

Ainda que grande parte do corpo de conhecimentos feministas tenha surgido no contexto da ciência moderna, é em virtude da crítica a seus pressupostos que este atinge legitimidade. Con- testando o viés androcêntrico da Ciência Moderna, o MF promoveu o desenvolvimento de formas alternativas de análise das relações entre homens e mulheres (Neves \& Nogueira, 2003), e provocou um processo de reconstrução teórica, descrito por Benhabib:

...[o MF] levou a uma significativa reestruturação de nossa tradição teórica a partir de uma perspectiva feminista. Após uma fase inicial de "desconstrução", a tradição intelectual ocidental, na qual os teóricos feministas revelaram a cegueira do gênero, assim como a tendenciosidade dessa herança, começou a tarefa da "reconstrução" teórica feminista. Enfocando experiências concretas das mulheres nas culturas, na sociedade e na história, os teóricos feministas indagaram como a mudança de perspectiva dos pontos de vista dos homens para o das mulheres poderia alterar as categorias fundamentais, a metodologia e o entendimento da ciência e da teoria ocidentais (1987, p.6).

Hall (1999) enfatiza sua importância para que se pensasse em termos de política de identidade, para o descentramento do sujeito e para a politização da subjetividade, pontos estes extremamente relacionados ao campo de produção da ciência psicológica.

No entanto, a entrada do MF no campo de produção psi não se deu sem apontar contradições e a necessidade de reposicionamentos desta disciplina. Longe de uma aproximação passiva, o MF impôs algum desassossego às teorias e práticas psicológicas, questionando suas afirmações, suas verdades e os efeitos produzidos por elas. É atentando para estas questões que propomos, neste trabalho, abordar os desafios introduzidos pelo MF à Psicologia e as repercussões de tais questionamentos em suas práticas.

\section{A ciência psicológica}

A tradição positivista da Psicologia pode ser melhor entendida se considerarmos que ela é herdeira de correntes do pensamento europeu do século XVIII, que têm suas bases no Racionalismo

3 Utilizaremos as iniciais MF para designar Movimento Feminista sem, com isso, pretender apresentá-lo como unificado e coeso em suas muitas e, por vezes contraditórias, formas de pensar a questão das mulheres. 
- surgido a partir da Revolução Francesa - cujo conceito de ciência era de um saber superior e, portanto, acessível a poucas pessoas privilegiadas. Este paradigma impulsionado especialmente pela produção de conhecimentos no campo das ciências naturais tomava como princípios epistemológicos e metodológicos a neutralidade, previsibilidade e generalização, sendo o sujeito do Racionalismo concebido como ser autônomo, que bastava a si mesmo. A busca da verdade e, quase que a garantia de encontrá-la, estariam vinculadas ao rigor do método científico (Bernardes, 1998). Essa maneira de compreender o mundo, apoiada no cientificismo do culto ao método e à razão, buscou transformar/traduzir as relações sociais em verdades absolutas e incontestáveis, afirmando a possibilidade de obtenção de resultados objetivos e corretos, originados especialmente em um de seus pressupostos: a neutralidade e, portanto, a primazia do conhecimento científico sobre as outras formas de saber/conhecer.

O reconhecimento da Psicologia como ciência, em finais do século XIX, deu-se sob a influência das correntes filosóficas de seu tempo. Desde o Iluminismo, passando pelo Positivismo, até chegar ao Humanismo, a Psicologia incorporou e produziu uma série de conceitos e idéias que ajudaram a delinear práticas adotadas nos seus vários campos de ação, o mesmo acontecendo em relação às diversas noções de sujeito das quais tem se utilizado.

Do Positivismo, a Psicologia adotou a noção de método científico, baseado na verificabilidade das informações. Para responder a este requisito, abandonou a observação desinteressada e passou a buscar a disciplina metodológica (Figueiredo, 1991). Entretanto, esses métodos calcados nos procedimentos originados nas ciências naturais e basicamente descritivos, não atendiam às peculiaridades dos processos psíquicos. Estes não ficavam circunscritos ou "acessíveis" às limitadas e rigorosas prescrições do método científico. Alguns dos pesquisadores da primeira metade do século XX acreditavam que utilizando métodos quantita- tivos, suas práticas atenderiam aos critérios científicos que legitimariam a Psicologia. Entre outros efeitos, a influência do Positivismo provocou um reducionismo na construção de conhecimentos da Psicologia; não é por acaso que tantas técnicas foram desenvolvidas no sentido de mensurar comportamentos e tantas questões ideológicas transversalizam o universo da produção psicológica ${ }^{4}$ (Bernardes, 1998).

A concepção de sujeito, nesta perspectiva, definia-o como um ser autônomo, 'senhor da natureza', dotado de racionalidade, cujo representante era o homem branco e burguês (Pedreira, 1999). Para transcender a natureza, o sujeito racional apoiava-se no distanciamento dos aspectos que o ligavam a instintos e impulsos 'animais' (Figueiredo, 1991). Por oposição, o sujeito empírico era desqualificado por se basear nos sentidos - que enganariam, falhariam e iludiriam - para construir seu conhecimento, que seria, por conseqüência, impreciso. Para que o conhecimento fosse considerado fidedigno era preciso que fosse afastado de toda ligação com aspectos físicos que o remetessem à natureza em sua concretude e especificidade (Violi, 1990) e desligar-se de sua subjetivida$\mathrm{de}^{5}$. Só era digno de confiança e legitimado o conhecimento obtido pelo método racionalista, passível de verificação e repetição.

Assim, o homem/sujeito era o senhor da razão e o modelo da ciência, e o método científico sua prerrogativa, ficando as mulheres, fortemente associadas à sua função reprodutora, alijadas desse campo. Enquanto o homem foi posicionado no lugar do padrão, de referência, tanto nos aspectos relativos à ciência quanto ao estabelecimento de normas sociais, às mulheres era atribuída uma razão inferior o que estabeleceu seu lugar como o Outro nessa relação, a partir da suposição de uma indole (feminina) intuitiva e, por isso, pouco confiável. A validação da centralidade do sujeito da razão (masculino) vinculava-se, entre outras coisas, a manter fora de discussão as questões relativas à corporeidade e sexualidade, logo, as diferenças e a subjetividade feminina, as quais estas

\footnotetext{
4 A questão do reducionismo pode não residir necessária ou exclusivamente nas técnicas de mensuração, mas nas formas como estas são utilizadas e na sua pretensão à apreensão da totalidade do sujeito. Do mesmo modo, não se trata de afirmar uma desejável isenção, seja ela ideológica ou política. É justamente a explicitação das vinculações políticas (em algumas vertentes chamadas ideológicas) uma das principais contribuições e compromissos introduzidos pelo MF na Psicologia. Pretende-se aqui pontuar que, enquanto vinculada a uma perspectiva positivista de ciência, não houve o reconhecimento ou o questionamento das implicações da psicologia com tais interesses, na medida em que se afirmava o conhecimento científico como neutro.

5 Aqui subjetividade era entendida como algo do interior do sujeito, em uma concepção individualista (Hall, 1999).
} 
eram associadas. Num primeiro momento, o sujeito moderno/cartesiano/da razão é apresentado como aquele que está no centro do universo; o sujeito que com seu conhecimento e suas capacidades pode dominar a Natureza, é o sujeito racional, o sujeito que conhece. Para tanto, era preciso que ele enfrentasse o dualismo mente corpo, colocando sua capacidade de pensar acima de sua corporeidade (que o colocava como parte da Natureza e não como seu senhor). Por outro lado, provavelmente ligado ao grande discurso religioso que precedeu o discurso científico, as mulheres eram primordialmente associadas as suas funções reprodutivas, à idéia de que elas agiam guiadas por instintos (como o materno, por exemplo) e que seu corpo apresentava alterações incompreensíveis na época (menstruação, alterações hormonais, etc.), afastando-as da racionalidade e aproximando-as da Natureza. Ora, o discurso científico e filosófico atribuiu às mulheres os aspectos humanos que faziam parte da natureza e lembravam sua animalidade, como a sexualidade, as especificidades do corpo, a diferença, enquanto que o homem figurava como um ser de racionalidade, unificado. Nesse momento os argumentos construídos a partir da racionalidade científica foram empregados para justificar um modelo que relegava as mulheres à exclusão social.

Para a Psicologia, que buscava sua afirmação como ciência, a adoção do sujeito racional e a utilização do método científico como prática pareceu ser a melhor escolha, apesar de algumas especificidades: a complexidade do sujeito psicológico e a impossibilidade da apreensão de questões que envolvem o psiquismo por meio da utilização da metodologia científica positivista.

Parece haver aí uma limitação que, entretanto, não intimidou a jovem ciência de enfatizar o estudo do comportamento individual, como expressão de uma dimensão interior, uma suposta substância psicológica. Para tanto, lançou mão de recursos e teorias que hipoteticamente lhe permitiriam estabelecer padrões para os comportamentos observáveis, expressos, por exemplo, pelo funcionalismo ou behaviorismo, sugerindo, na maioria, das vezes, uma relação direta de causa e efeito.

Assim não é de causar estranheza que a Psicologia, ao abordar as questões relativas às mulheres e às relações de gênero, tenha direcionado seus esforços para o estudo das diferenças sexuais e aos aspectos privados da relação entre os gêneros. Esta tradicionalmente limitou-se aos espaços das experiências individuais, da família, do inconsciente, deixou de problematizar os espaços das experiências coletivas. Do mesmo modo, apesar de algumas exceções na produção mais recente $^{6}$, a Psicologia, como disciplina, pouco se ocupou de desenvolver um instrumental teórico que tornasse possível este tipo de abordagem. Talvez porque a maior parte dos escritos sobre as mulheres, antes do MF, tenha sido produzida por homens, as mulheres foram construídas por meio da afirmação de oposição aos homens. Também por isso não causa estranhamento a utilização da noção de papéis sexuais dentro da lógica binária de inclusão/exclusão, por oposição, ou seja, um é o que o outro não pode ser.

Ao lançar mão do discurso originário das ciências naturais, a Psicologia aderiu também a uma visão biologicista sobre as mulheres, vinculando sua participação social à função reprodutiva e reafirmando (muitas vezes restringindo) sua importância no meio familiar, espaço privado por definição.

Reforçando a crença de que homens e mulheres são intrinsecamente diferentes, a Psicologia terminou por fortalecer a fixação de papéis específicos para homens e mulheres. Assim, às mulheres caberiam as virtudes ditas femininas a aos homens as virtudes ditas masculinas, determinando a cada um o seu espaço social, influenciando e servindo como justificativa até mesmo para a divisão sexual do trabalho.

Com o surgimento de novas concepções filosóficas, especialmente com o pensamento marxista e a psicanálise, o sujeito da razão que nunca chegou a responder completamente às questões da Psicologia, deixou de ser visto como o único referente da ciência. Este cede espaço para outras versões teóricas na abordagem do sujeito, dentre as quais a constituição da noção sociológica de indivíduo. Esta noção, associando as proposições da biologia darwiniana e das ciências sociais, constituiu um sujeito biologizado e socializado. Assim, a "'internalização' do exterior no sujeito e a 'externalização' do interior através da ação no mundo

6 No campo da Psicologia, algumas pesquisadoras que têm se ocupado desta questão mais recentemente são Conceição Nogueira, Ligia Amâncio, Janis Bohan, Jeanne Marecek, Mary Gergen. 
social constituem a descrição sociológica primária do sujeito moderno e estão encapsuladas na teoria da socialização" (Hall, 1992, p. 31).

Nesta concepção, o sujeito é, como bem nos diz Jurandir Costa (1996), uma rede lingüística de crenças e desejos, um ser de linguagem, um conjunto de crenças sobre si mesmo; de definições, interpretações, versões e imagens que tem sobre si. Todas estas versões são construtos lingüísticos e, como tal, um fenômeno social. Por conseguinte, toda imagem ou noção do que é um sujeito é pública, social ou cultural e só tem sentido em dado contexto histórico; em dado vocabulário; em dada forma de vida etc. De algum modo, acreditamos nessas versões e nos constituímos por meio delas, mesmo que não consigamos descrever as razões que nos levam a fazer algumas escolhas. E Jurandir Costa afirma que a determinação da escolha de um rol de razões que aceitamos como verdadeiras são nossos interesses mundanos; o que vai determinar a versão que aceitamos são os jogos de verdade, os jogos de sentido, os jogos de poder nos quais estamos envolvidos.

Das diferentes visões de sujeito operadas pela Psicologia, a concepção humanista de sujeito (autônomo, responsável, reflexivo e crítico) parece ser aquela que mais se coaduna com o projeto da ciência psicológica voltada para o plano de uma crítica histórica e que se aproxima das ciências sociais e da filosofia. Pode-se dizer que foi a adoção dessa concepção de sujeito que permitiu à Psicologia aceitar os questionamentos propostos pelo Movimento Feminista.

\section{0 encontro com o Movimento Femi- nista}

O encontro entre o MF e a Psicologia não se deu sem conflitos. Contestando pressupostos científicos consagrados até então, propondo uma visão relacional da sociedade e afirmando que homens e mulheres constroem as realidades sociais (Neves \& Nogueira, 2003), o MF questionou muitos dos pressupostos em que se baseava a Psicologia, positivista, que como tal, possuía uma forte marca androcêntrica e uma nítida pretensão universalizante. O MF propôs a consideração dos interesses de um grupo em contraposição à pretensa neutralidade científica, centrada no indivíduo, que desconsiderava o contexto social no qual ele se inseria e, por conseqüência, negava-lhe a possibilidade de uma ação coletiva (Nogueira, 2001a). A recente aproximação da Psicologia com o movimento feminista, somando-o ao seu campo de produção inicialmente, mas não exclusivamente, pó meio do discurso de gênero, permitiu que ela assumisse e reafirmasse uma preocupação com o público e com o social, portanto político.

Conceição Nogueira (2001b), em seu artigo Contribuições do Construcionismo Social a uma Nova Psicologia do Gênero, faz um apanhado das diversas abordagens teóricas das ciências sociais e as correspondentes práticas em relação à questão de gênero, relacionando-as com suas implicações para o campo da Psicologia.

Segundo esta autora, na perspectiva empiricista duas são as abordagens citadas: a essencialista e a da socialização. Na primeira, a essencialista, que predominou até metade do século XX, gênero era entendido a partir das diferenças inatas e estáveis entre os sexos e considerado como um traço que descrevia as personalidades, separado do contexto sociopolítico. Na perspectiva da socialização, corrente predominante nos anos 60 e 70, gênero passou a ser concebido como resultado das forças sociais e culturais aprendidos por modelagem e imitação. Sob essa ótica, masculinidade e feminilidade seriam comportamentos aprendidos, o que permitiu o surgimento do conceito de androgenia, que afirma que uma pessoa pode apresentar características femininas e masculinas simultaneamente. Tanto uma como a outra são criticadas por seu caráter prescritivo a serviço da ordem social estabelecida, e por permanecerem dentro da concepção dicotômica de feminino e masculino e com isso reforçarem as diferenças de gênero consideradas reais. Mesmo trazendo novas idéias e enfatizando que gênero é aprendido e não inato, essa abordagem continua a tratá-lo como uma característica permanente e estável dos indivíduos. Para a Psicologia, tais abordagens implicaram por um lado em uma produção teórica que se centrou na naturalização e essencialização de comportamentos masculinos e femininos; por outro lado, nos estudos desenvolvidos a partir da teoria do papel social, que afirma e restringe as diferenças entre homens e mulheres ao resultado dos papéis sociais que regulam o comportamento humano na sociedade. Em ambos os casos, tem-se a reafirmação de duas posições dicotômicas, onde para cada sexo deveria corresponder uma posição ou comportamento de gênero. 
Segundo Nogueira (2001b), é para fugir da armadilha do pensamento dicotômico e desenvolver um "projeto psicológico feminista" que surgiu, nos anos 80, uma terceira perspectiva, denominada pós-moderna ou pós-feminista. Essa abordagem nega a supremacia do sujeito da razão ao reconhecer a fragmentação da identidade e centralizar seus estudos nas próprias mulheres, seu discurso, sua produção de conhecimento. Valorizando a linguagem e as relações sociais, negando a busca por uma verdade universal e absoluta. $\mathrm{O}$ ser humano passa a ser visto como parte do sistema social e cultural no qual foi constituído, produto de discursos que têm em si uma rede de relações de poder:

A psicologia, em tal perspectiva, torna-se o estudo do ser socialmente construído, o produto de discursos histórica e culturalmente contingentes, discursos que trazem consigo uma rede complexa de relações de poder. A pessoa fica como que 'encaixada' num sistema histórico, social e político do qual não pode ser retirada e estudada independentemente (Nogueira, 2001b, p.146).

Ao adotar para si alguns dos pressupostos feministas como princípios orientadores - ainda que não de maneira uniforme - a Psicologia coloca-se em uma posição menos amarrada ao modelo positivista de ciência. A partir deste diálogo, além de buscar compreender não só os efeitos do gênero na construção do conhecimento, mas também de outros sistemas de classificação, como raça e orientação sexual, por exemplo, este campo de conhecimento pôde tornar-se um meio de resistência, inovação e mudança social. Apesar dos conflitos epistemológicos e metodológicos com os quais se depara, a Psicologia tem, na opinião das teóricas feministas, potencial como mecanismo para a construção de um mundo melhor e na defesa de valores como igualdade e justiça social (Neves \& Nogueira, 2003).

As práticas terapêuticas na Psicologia não são (e não podem ser) livres de valores nem apolíticas, na medida em que não existem senão enquadradas em tempos históricos, especificidades culturais e conjunturas políticas, da mesma forma que os/as terapeutas não são tábuas rasas, sem passado nem presente (Neves \& Nogueira, 2003, p. 18).
O MF provocou uma reestruturação da tradição teórica nas ciências sociais de modo geral e na Psicologia em particular. Hoje podemos observar as repercussões de seus questionamentos nas práticas e pesquisas psicológicas. A adesão, pelo feminismo, à idéia de que o conhecimento é construído socialmente, abre possibilidades impensáveis em um modelo teórico normalizador. A recusa à crença de que não é possível trabalhar com pessoas a partir de uma visão neutra, assumindo um ativismo social que até bem pouco tempo era visto como problemático para o reconhecimento da seriedade de um trabalho, tem permitido pensar a Psicologia como uma prática inclusiva.

No que concerne especificamente ao modo como a Psicologia passou a dirigir-se às mulheres, um efeito sem dúvida muito importante desse encontro tem sido a despatologização da condição feminina (Neves \& Nogueira, 2003), tão freqüente em práticas calcadas na biologização, motivando, assim, a construção de relações sociais menos desiguais.

De igual importância é a mudança ocorrida na forma de tratar a questão do público e do privado que originou uma evidente mudança na lógica de intervenção, desconstruindo o mito do espaço familiar e íntimo como idílico. A Psicologia passou a reconhecer que o público e o privado seriam instâncias simbólicas do processo coletivo de construção da realidade, que se constituem não como extremos de um contínuo, mas como momentos de um processo e que a qualificação como público ou privado só pode ser feita por referência recíproca.

A intervenção feminista na Psicologia, procurando comprometidamente estreitar a distância entre o pessoal e o político, entre o privado e público, entre as mulheres e os homens, presta um enorme contributo na prevenção e na erradicação de fenômenos violentos praticados na intimidade. Os modelos feministas, ao serem adaptados pela Psicologia, desempenham um papel de enorme importância no desenvolvimento de um pensamento crítico que desafie a tentativa de padronização e de classificação dos comportamentos humanos. (Neves \& Nogueira, 2003, p. 18).

A Psicologia, ao situar sua prática numa lógica de mudança social, sem perder de vista a 
análise das relações interpessoais como produtoras de linguagens diferenciadas de poder e de responsabilidade social, coloca a ciência a serviço das necessidades das pessoas. Portanto, abordar as repercussões da aproximação do MF com a Psicologia extrapola a obviedade de novas formas de análise das relações de gênero. O que esta aproximação tem indicado - ao promover espaços para a inclusão de novas abordagens sobre questões como identidades e diferenças, público e privado, a dimensão política da teoria, entre outras temáticas emergentes no contemporâneo - é a complexidade onde se enreda a produção do sujeito contemporâneo, independentemente do rótulo identitário que se lhe atribua (mulher, homem, branco, negro, asiático, etc.). Mais do que isso, uma complexificação do próprio olhar "da ciência", que se descentra do foco "objeto", para dar lugar às relações nas quais se constroem os sujeitos/objetos. Pode-se conceber, assim, um conhecimento crítico e reflexivo em relação às próprias práticas que institui e às verdades que produz.

\section{Referências}

Benhabib, S. \& Cornell, D. (1987). Feminismo como crítica da modernidade. Rio de Janeiro: Rosa dos Tempos.

Bernardes, J. (1998). História. In: Jacques, M. G. et al. Psicologia Social Contemporânea. Petrópolis: Vozes.

Costa, J. F. (1996) Richard Rorty e a construção da subjetividade humana. Recuperado em 12 jun.2003.http:www.jfreirecosta.hpg.ig.com.Br/ C i ên cia_e _ E d u c a çã o/9/A r tig o s / subjetividadehumana.html>
Figueiredo, L. (1996). Matrizes do pensamento psicológico. Petrópolis: Vozes.

Hall, Stuart.(1992) A questão da identidade cultural. In Stuart Hall; D. Held \& T. McGrew (orgs.). Modernity and its futures. (Tradução: Guacira Lopes Louro e Tomaz Tadeu da Silva). (pp. 274316). Cambridge: Polity/Open University.

\section{Hall, S. (1999). A identidade cultural na pós-}

modernidade. Rio de Janeiro: DP\&A.

Neves, S. \& Nogueira. C. (2003) A psicologia feminista e a violência contra as mulheres na intimidade: a (re)construção dos espaços terapêuticos. Psicologia \& Sociedade, 15, (2).

Nogueira, C. (2001a) Feminismo e discurso do gênero na psicologia social. Psicologia e Sociedade. UFRGS, 13(1), 107-128.

Nogueira, C. (2001b) Contribuições do construcionismo social a uma nova psicologia de gênero. Cadernos de Pesquisa, Fundação Carlos Chagas, (112), 137-153.

Pedreira, E.B. (1999). Público e privado - sobre feministas liberais: argumentos em um debate sobre os limites da dimensão política. In Cidadania e feminismo. São Paulo:Melhoramentos.

Violi, P. (1990). Sujeto lingüístico y sujeto feminino. In Colaizzi, G. Feminismo y teoría del discurso. Madrid: Catedra.

Recebido em/Received in: 15/12/2004 Aprovado em/Approved in: 21/01/2005 